\title{
Self-Esteem dan Motivasi Altruistik Siswa yang Mengikuti Kegiatan Pramuka di Sekolah
}

\author{
Zelfa Yuliza Putri ${ }^{1}$, Dosi Juliawati ${ }^{2}$, Hengki Yandri ${ }^{3}$ \\ 1,2,3 Jurusan Bimbingan dan Konseling Pendidikan Islam, Institut Agama Islam Negeri Kerinci
}

*Corresponding author, e-mail: dosi@konselor.org

\begin{abstract}
The study aims to uncover a self-esteem relationship with the altruistic motivations of students who participate in scouting activities. This research method uses a quantitative approach with a correlational descriptive method with a population of 104 people who come from students of State Junior High School 7 Sungai Penuh who participated in Scout activities, then samples were taken using a simple random sampling formula then obtained a sample of 83 people. The tool reveals self-esteem data in an adaptation of the Coopersmith Self-Esteem Inventory (CSEI) and the altruistic motivation data researchers developed themselves, namely the Altruistic Motivation Scale (SMAL). The data of the study results were processed and analyzed descriptively to see the distribution of frequencies and then conducted a correlation test using Pearson Product Moment Correlation. The results of this study revealed that the self-esteem and altruistic motivation of students who participated in scouting activities in school were on average in the world.
\end{abstract}

Keywords: Self-Esteem, Altruistic Motivation, Scout

\section{Pendahuluan}

Sekolah merupakan lembaga untuk para siswa guna menerima pendidikan dan pengawasan dari guru ke arah tujuan yang lebih baik, agar dapat membekali anak dengan pengetahuan dan kecakapan hidup yang akan dating (Desmita, 2014). Keberhasilan pendidikan tidak hanya tergantung pada pendidik yang selalu di tuntut dapat mengajar secara profesional saja, melainkan peran aktif siswa di dalam proses belajar juga sangat menentukan keberhasilan proses pendidikan (Aliwanto, 2017).

Siswa adalah salah satu komponen manusiawi yang menempati posisi sentral dalam proses belajar mengajar. Di dalam proses belajar mengajar, siswa sebagai pihak yang ingin meraih cita-cita, memiliki tujuan dan kemudian ingin mencapai secara optimal (Arifin, 2013). Belajar merupakan salah satu konsep yang amat mendasar dari psikologi. Setiap orang belajar untuk hidup. Tanpa belajar, seseorang tidak akan dapat mempertahankan dan mengembangkan dirinya, dan dengan belajar, seseorang mampu berbudaya dan mengembangkan harkat kemanusiaannya. Inti perbuatan belajar adalah sebagai upaya untuk menguasai sesuatu yang baru dengan memanfaatkan yang sudah ada pada diri individu (Salahudin, 2010). Tujuan pembelajaran adalah membantu para siswa agar memperoleh berbagai pengalaman. Melalui pengalaman itu, tingkah laku siswa bertambah, baik kuantitas maupun kualitasnya. Tingkah laku yang dimaksud meliputi pengetahuan, keterampilan, serta nilai atau norma yang berfungsi sebagai pengendali sikap dan perilaku siswa. Proses belajar mengajar perlu direncanakan agar pelaksanaan pembelajaran berlangsung dengan baik dan mendapatkan hasil yang diharapkan (Hasan, 2013). 
Pola sikap dan perilaku yang terbentuk pada setiap individu melalui sebuah proses yang melibatkan banyak faktor, termasuk salah satunya adalah faktor psikologis. faktor psikologis yang dibutuhkan untuk membentuk pola sikap dan perilaku sehat pada individu adalah pemenuhan selfesteem dan didukung dengan adanya motivasi altruistik. Sarwono menyatakan altruisme adalah tindakan individu untuk menolong orang lain tanpa adanya keuntungan langsung bagi si penolong. Individu tersebut menolong untuk kesejahteraan orang lain semata tanpa, motivasi untuk kepentingan diri sendiri (Nurdianto, 2016). Menurut Berkowits, Gunningham dkk dalam Myers bahwa menolong mengurangi mood yang buruk dan meningkatkan mood yang baik, positif pada kenyataannya mendatangkan pikiran dan harga diri yang positif yang mempengaruhi kita untuk berperilaku positif (Afivah, 2016). Remaja yang memiliki harga diri tinggi rentan untuk memperlihatkan perilaku prososial maupun perilaku anti sosial (Afivah, 2016). Individu yang memiliki tingkat kecenderungan yang tinggi untuk, melakukan tindakan pro-sosial, biasanya memiliki karakteristik kepribadian, yakni memiliki harga diri yang tinggi, rendahnya kebutuhan akan persetujuan orang lain, rendahnya menghindari tanggung jawab dan lokus kendali yang internal (Afivah, 2016).

Berdasarkan hasil observasi awal yang dilakukan oleh peneliti pada tanggal 26 Oktober 2019 di SMP Negeri 7 Sungai Penuh, terdapat siswa kurangnya sikap saling tolong menolong satu sama lain. Mereka hanya cenderung membantu teman dekatnya saja, juga membantu ketika diminta dan disuruh oleh guru. Bergaul sesama geng/kelompok saja, Banyak terlihat dari mereka tidak kompak saat bermain di luar atau pun belajar di dalam ruangan. Selain itu, juga terdapat harga dirinya masih rendah, seperti kurang bergaul, minder, dan juga kurang aktif. terdapat siswa masih kurang percaya diri. Misalnya, ketika berbicara dan menyampaikan sesuatu, kurangnya Sikap sopan santun.

Dalam proses belajar pembinaan dan pengembangan peserta didik dilakukan agar siswa mendapatkan berbagai macam pengalaman belajar untuk bekal di kehidupan yang akan datang, dapat menumbuhkan harga diri serta mengubah watak dan perilaku seseorang dari yang tidak baik menjadi baik. Salah satu wadah dalam pembinaan kegiatan siswa disekolah adalah melalui kegiatan ekstrakurikuler salah satunya kegiatan pramuka. Dalam Undang-Undang Republik Indonesia Nomor 20 Tahun 2003 BAB V Pasal 12 ayat 1b disebutkan "setiap peserta didik pada setiap satuan pendidikan berhak mendapatkan pelayanan pendidikan sesuai dengan bakat, minat dan kamampuannya". Dari penjelasan tersebut bahwa sekolah merupakan wadah dan sarana untuk mengembangkan bakat serta kemampuan siswa. Jadi kegiatan ekstrakurikuler harus diprogramkan sedemikian rupa untuk memberikan pengalaman kepada siswa.

Sejak diberlakukan kurikulum nasional atau kurikulum 2013, pendidikan pramuka merupakan kegiatan ekstrakurikuler yang wajib diikuti oleh peserta didik, dan juga diperkuat dengan adanya Undang-Undang No. 12 tahun 2010 tentang gerakan pramuka dan Peraturan Menteri Pendidikan dan Kebudayaan No. 63 tahun 2014 dijelaskan bahwa: (a) pendidikan kepramukaan dilaksanakan untuk menginternalisasikan nilai ketuhanan, kebudayaan, kepemimpinan, kebersamaan, sosial, kecintaan alam, dan kemandirian pada peserta didik, (b) bahwa nilai-nilai dalam sikap dan keterampilan sebagai muatan kurikulum 2013 dan muatan pendidikan kepramukaan dapat bersinergi secara koheren, (c) bahwa sehubungan dengan pertimbangan sebagaimana maksud pada huruf a dan b perlu menetapkan peraturan menteri kependidikan dan kebudayaan tentang pendidikan 
kepramukaan sebagai kegiatan ekstrakurikuler wajib pada pendidikan dasar dan pendidikan menengah".

Dalam Anggaran Rumah Tangga (ART) Gerakan Pramuka BAB. IV BSG. 1 pasal 8 ayat 2 dijelaskan bahwa: "Pendidikan kepramukaan merupakan pendidikan non formal dalam sistem pendidikan sekolah yang dilakukan dialam terbuka dalam bentuk kegiatan yang menarik, menantang, menyenangkan. Sehat, teratur dan terarah dengan menerapkan prinsip dasar kepramukaan dan metode kepramukaan, agar terbentuk kepribadian dan watak yang berakhlak mulia, mandiri, peduli, cinta tanah air, serta memiliki kecakapan hidup". Melalui kegiatan ekstrakurikuler yaitu pramuka diharapkan dapat menumbuhkan harga diri serta mengubah watak dan perilaku seseorang dari yang tidak baik menjadi baik. Sel- esteem (harga diri) adalah keyakinan dan kemampuan untuk bertindak dan menghadapi tantangan hidup ini. Keyakinan dalam hak untuk bahagia, perasaan berharga, dan layak. Cara memandang dan merasakan diri sendiri yang akan mempengaruhi seseorang dalam berperilaku. Cara pandang dan merasakan diri ini terbentuk dari pengalaman dalam keluarga, sekolah, hubungan pertemanan dan lingkungan sosial. Self-esteem merupakan salah satu aspek kepribadian yang merupakan kunci dalam pembentukan perilaku seseorang, karena akan sangat berpengaruh pada proses berpikir, tingkat emosi, keputusan yang diambil pada nilai-nilai tujuan hidup seseorang yang memungkinkan seseorang mampu menikmati dan menghayati kehidupan. Ketika self-esteem yang terbentuk dalam diri siswa kurang baik kemungkinan akan mengganggu proses pembelajaran siswa tersebut (Sylvia, 2016).

Self-esteem dapat didefinisikan sebagai seberapa besar kita menyukai diri kita sendiri. Roger meyakini bahwa kita memiliki citra diri dalam pikiran kita seperti keadaan kita sekarang, sekaligus citra diri kita yang ideal (ideal-self), yaitu citra diri yang kita inginkan. Jika kedua citra itu kongruen (artinya sama) kita akan mengembangkan harga diri yang baik. Perkembangan kongruen dan harga diri bergantung pada penghargaan positif tak bersyarat (unconditional positif regard) dari orang lain berupa penerimaan, cinta, dan kasih sayang (Asytharika, 2016). Harga diri (self esteem) merupakan evaluasi yang dibuat individu dan kebiasaan memandang dirinya, terutama sikap menerima, menolak, dan indikasi besarnya kepercayaan individu terhadap kemampuan, keberartian, kesuksesan, keberhargaan. Secara singkat harga diri adalah "personal judgment" mengenai perasaan berharga atau berarti yang diekspresikan dalam sikap-sikap individu terhadap dirinya (Alifah, 2016).

Gerakan pramuka menjadi salah satu pembentuk karakter bangsa diantaranya berjiwa patriot, nasionalisme, cinta kepada tuhan, cinta kepada sesama, dan cinta kepada alam, mengajarkan gotong royong, disiplin, mandiri, saling menolong, menghargai, kepedulian sosial dan lingkungan (Erliani, 2016). Kepramukaan menggunakan metode outdoor studi anggota diajarkan untuk dekat dengan lingkungan dan peduli kepada orang lain sebagaimana catatan pendiri pramuka, Baden Powell, bahwa menjadi orang baik tidak hanya selalu berdoa tapi bagaimana berusaha keras untuk berbuat baik dan peduli pada orang lain (Erliani, 2016).

Merujuk pada uraian sebelumnya dapat disimpulkan, bahwa self esteem dapat dipengaruhi oleh motivasi altruistik siswa. Semakin tinggi harga diri seorang remaja semakin tinggi pula perilaku altruisme dan sebaliknya, semakin rendah harga diri seorang remaja semakin rendah pula perilaku altruisme. Kemudian berdasarkan penelitian yang di lakukan oleh Fitri Nurri Afivah tahun 2016 menugungkapkan terdapat gejala bahwa siswa yang aktif dalam organisasi ekstrakurikuler, jarang mendapatkan sanksi sekolah dan siswa yang mampu mengutarakan pendapat kepada teman- 
temannya dan pendapat itu diterima oleh teman-temannya, dan lebih sering menolong kepada temannya, sebagai contoh ketika istirahat mereka rela membelikan snack (makanan ringan) untuk temannya. Berbeda dengan siswa yang tidak mengikuti kegiatan ekstrakurikuler dan tidak mau mengapresiasikan pendapanya didepan teman-temannya, mereka lebih cenderung membantu teman yang hanya dekat dengan dirinya saja. Dari paparan data dan hasl kajian teori sebelumnya, maka tujuan penelitian ini yaitu untuk mengungkap hubungan self-esteem dan motivasi altruistis siswa yang mengikuti kegiatan Pramuka di Sekolah

\section{Metode}

Penelitian ini menggunakan pendekatan kuantitatif dengan metode deskriptif korelasional yang dimanfaatkan untuk melihat hubungan antar dua variabel penelitian atau lebih (Sukardi, 2013). Adapun hubungan variabel yang dilihat pada penelitian ini yaitu antara self-esteem dengan motivasi altruistis siswa. Populasi penelitian ini yaitu siswa Sekolah Menengah Pertama Negeri 7 Sungai Penuh yang berjumlah 104 Orang, kemudian dengan menggunakan rumus simple random sampling maka diperoleh sampel sebanyak 83 orang.

Alat ungkap data self-esteem diadaptasi dari Coopersmith Self-Esteem Inventory (CSEI) yang terdiri dari aspek sosial diri, teman sebaya, orang tua dan akademis (Johnson et al, 1983) dengan hasil uji validitas dan reliabilitas $A$ hba Cronbach sebesar 0,675. Kemudian alat ungkap data motivasi altruistis peneliti kembangkan sendiri yaitu Skala Motivasi Altruistis (SMAL) yang terdiri dari aspek empati, sukarela dan keinginan membantu (Carpenter \& Myers, 2010) dengan hasil uji validitas dan reliabilitas Alpha Cronbach sebesar 0,544. Pengumpulan data dilakukan langsung mendatangi responden penelitian ke sekolah dengan meminta izin dari pihak sekolah untuk melakukan penelitian, kemudian setelah diizinkan selanjutnya peneliti bersama pihak sekolah memberikan skala self-esteem dan skala motivasi altuisme langsung kepada siswa yang menjadi sampel penelitian.

Data hasil penelitian yang telah dikumpulkan menggunakan CSEI dan SMAL kemudian diolah dan dianalisis secara deskriptif untuk melihat distrubusi frekuensi dari setiap aspek yang diukur, seterusnya dilakukan uji Pearson Product Moment Correlation dengan memanfaatkan bantuan aplikasi SPSS versi 21.00 for windows untuk melihat hubungan antara variabel self-esteem dengan motivasi altruistis siswa yang mengikuti kegiatan pramuka di sekolah.

\section{Hasil dan Pembahasan}

Hasil temuan penelitian ini tentang self-esteem dan motivasi altruistis siswa yang mengikuti kegiatan pramuka di sekolah bisa di lihat pada tabel berikut:

Tabel 1. Distribusi Frekuensi Self-Esteem Siswa yang Mengikuti Kegiatan Pramuka

\begin{tabular}{ccc}
\hline Kategori & Frekuensi & Persentase \\
\hline Rendah & 24 & 28.92 \\
Sedang & 36 & 43.37 \\
Tinggi & 23 & 27.71 \\
\hline
\end{tabular}

Pada tabel di atas bisa dilihat bahwa dari 83 orang responden, sebanyak 36 orang responden memiliki selfesteem pada kategori sedang atau sebesar 43,37\%. Namun demikian, masih ada 
sebanyak 24 orang responden dengan self-esteem rendah atau sebesar 28,92\% dan sebanyak 23 orang responden dengan self-esteem tinggi atau sebesar $27,71 \%$. Untuk lebih jelasnya bisa di lihat pada indikator berikut ini:

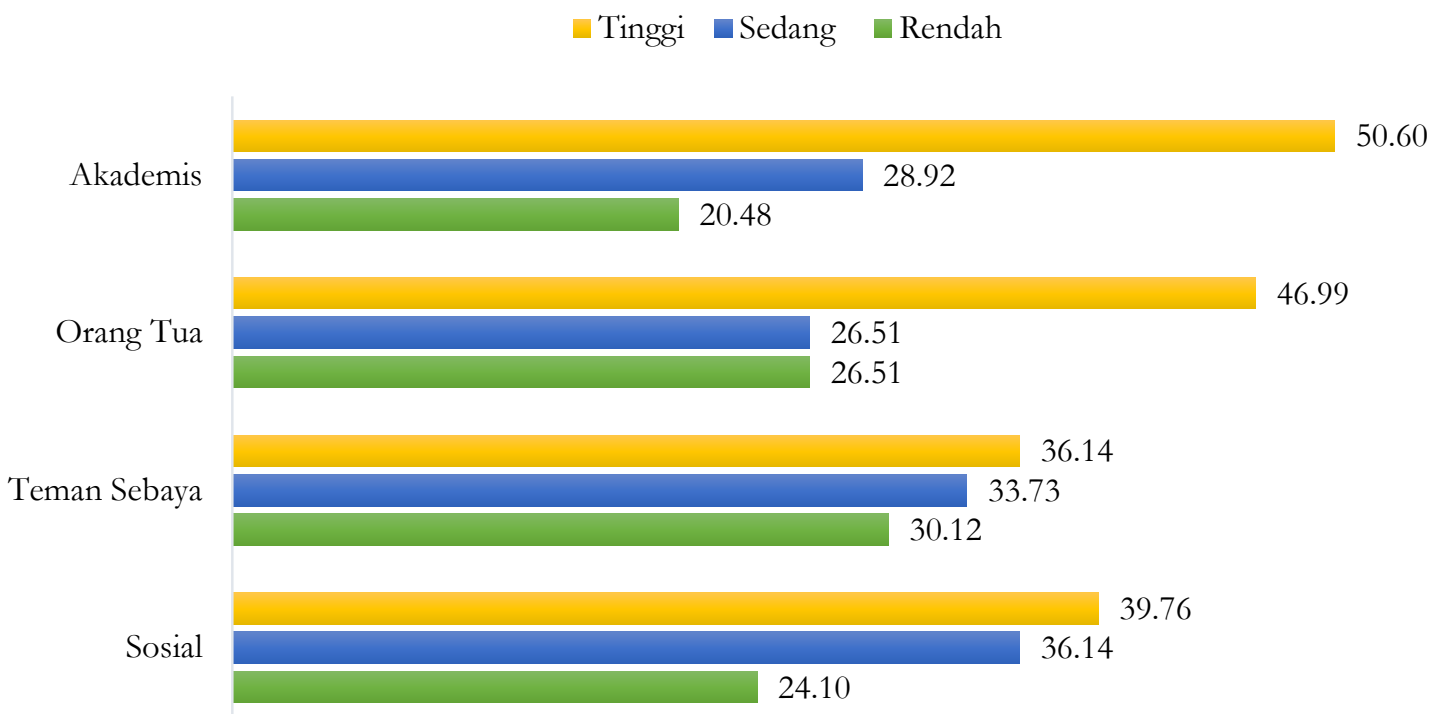

Diagram 1. Distribusi Persentase Indikator Self-Esteem Siswa yang Mengikuti Kegiatan Pramuka

Pada diagram di atas bisa dilihat pada setiap indikator self-esteem siswa rata-rata berada pada kategori tinggi, untuk indikator akademis sebesar 50,60 \%, indikator orang tua sebesar 46,99\%, indikator teman sebaya sebesar 36,14\% dan indikator sosial sebesar 39,76\%. Self-esteem seseorang ditentukan oleh seberapa besar individu tersebut merasa dirinya bernilai dan menyukai dirinya sendiri (Irawati \& Hajat, 2012). Seseorang yang memiliki self-esteem yang tinggi rentan untuk memperlihatkan perilaku pro-sosial maupun perilaku anti sosial, hal ini biasanya terjadi karena individu yang memiliki self-esteem tinggi memiliki kebutuhan akan persetujuan orang lain yang rendah, mudah menghindari tanggung jawab, memiliki locus of control internal dan self control yang baik (Afivah, 2016; Yandri., Juliawati., \& Afrifadela, 2020).). Hal ini terjadi karena ada beberapa faktor yang yang mempengaruhi self-esteem seseorang yaitu: usia, ras, etnis, pubertas, berat badan, dan jenis kelamin (Suhron, 2017)

Selanjutnya hasil temuan penelitian tentang motivasi altruistis siswa yang mengikuti kegiatan pramuka bisa dilihat pada tabel 2 berikut:

Tabel 2. Distribusi Frekuensi Motivasi Altruistis Siswa yang Mengikuti Kegiatan Pramuka

\begin{tabular}{ccc}
\hline Kategori & Frekuensi & Persentase \\
\hline Rendah & 26 & 31.33 \\
Sedang & 38 & 45.78 \\
Tinggi & 19 & 22.89 \\
\hline
\end{tabular}

Pada tabel 2 di atas bisa dilihat bahwa dari 83 orang responden, rata-rata motivasi altruistis siswa berada pada kategori sedang atau sebesar 45,78\%. Namun demikian, masih ada sebanyak 26 orang responden dengan motivasi altruistis rendah atau sebesar 31,33\% dan sebanyak 19 orang responden dengan motivasi altruistis tinggi atau sebesar $22,89 \%$. Untuk melihat tiap indikator motivasi altruistis siswa bias di lihat pada diagram berikut: 


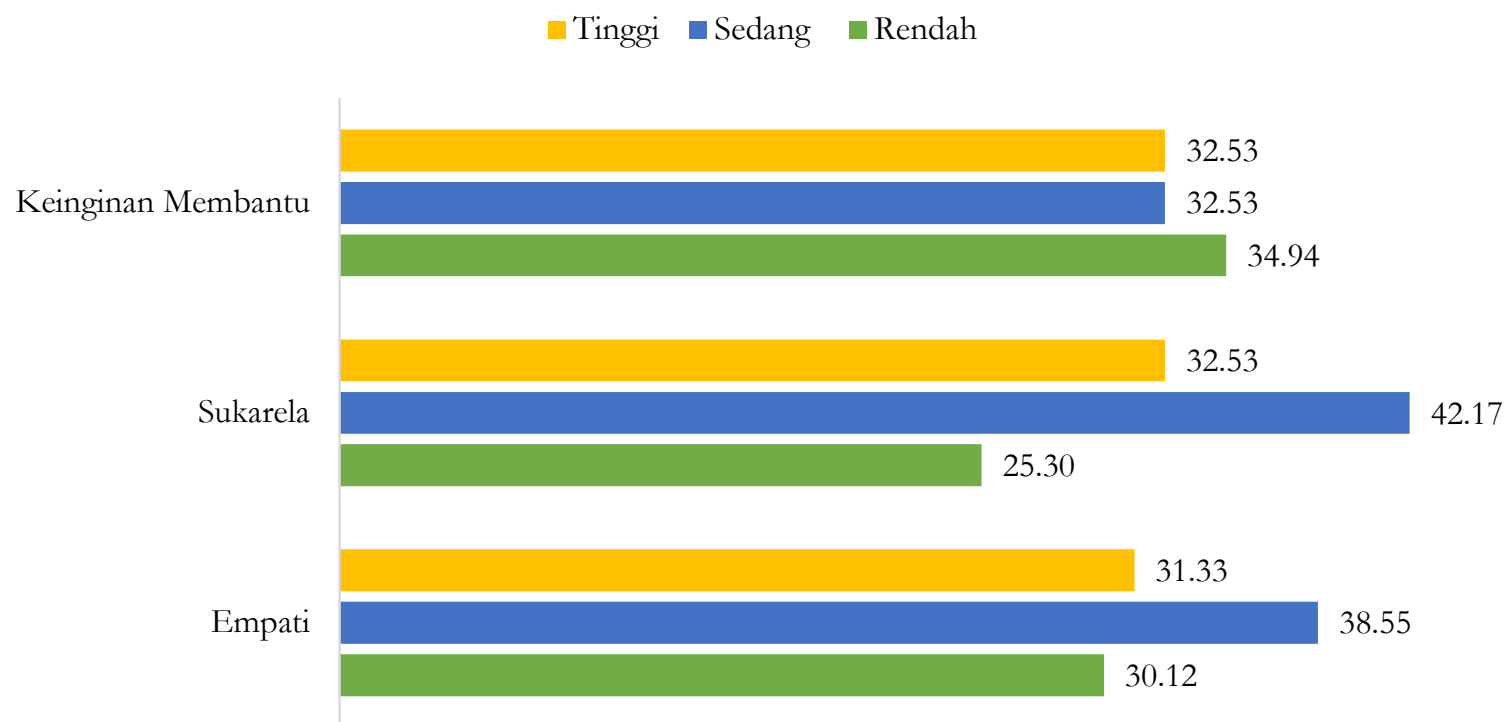

Diagram 2. Distribusi Persentase Indikator Motivasi Altruistis Siswa yang Mengikuti Kegiatan Pramuka

Pada diagram 2 di atas, bias dilihat bahwa motivasi altruistis siswa yang mengikuti kegiatan pramuka ditinjau dari indikator keinginan membantu rata-rata berada pada kategori rendah dengan persentase sebesar 34,94\%. Namun demikian, pada indikator sukarela rata-rata berada pada kategori sedang dengan persentase sebesar 42,17\% dan pada indikator empati rata-rata berada pada kategori sedang dengan persentase sebesar 38,55\%. Perilaku altruistis merupakan tindakan seseorang dalam menolong orang lain tanpa mengharap imbalan apapun tanpa ada motivasi kepentingan diri pribadi (Nurdianto, 2016; Yandri., Fikri., \& Juliawati, 2019). Sikap altruistis juga merupakan sebuah dorongan dalam diri individu untuk berkorban demi sesama atau niat menolong orang lain tanpa pamrih (Afivah, 2016). Menurut Myers ada lima karakteristik tingkah laku altruistis yaitu belief in a just word, tanggung jawab sosial, locus of control, dan egosentrik yang rendah (Nurdianto, 2016), hal ini di pengaruhi oleh beberapa hal sebagai berikut: pengaruh internal (perasaan, sifat individu, kepercayaan terhadap agama, aspek kepribadian) dan pengaruh situasi (Nisa, 2015).

Selanjutnya untuk melihat hubungan antara self-esteem dengan motivasi altruistis siswa yang mengikuti kegiatan pramuka di sekolah bisa dilihat pada tabel 3 berikut:

Tabel 3. Hasil Uji hubungan Self-esteem dengan Motivasi Altruistis Siswa yang Mengikuti Kegiatan Pramuka

\begin{tabular}{cccc}
\hline Variabel & $\boldsymbol{r}$ hitung & $\boldsymbol{r}$ tabel & Asymp. Sig. (2-tailed) \\
\hline $\begin{array}{c}\text { Self-Esteem } \\
\text { Motivasi Altruistis }\end{array}$ & 0,622 & 0,217 & 0,01
\end{tabular}

Pada tabel di atas diketahui nilai $r$ hitung besar dari nilai $r$ tabel yaitu $0,622>0,217$, hal ini berarti terdapat hubungan yang signifikan antara self-esteem dengan motivasi altruistis siswa yang mengikuti kegiatan pramuka di sekolah.

Baden Powell mengatakan bahwa menjadi orang baik tidak hanya selalu berdoa tapi bagaimana berusaha keras untuk berbuat baik dan peduli pada orang lain (Erliani, 2016). Gerakan pramuka menjadi salah satu pembentuk karakter bangsa diantaranya berjiwa patriot, nasionalisme, cinta kepada tuhan, cinta kepada sesama, dan cinta kepada alam, mengajarkan gotong royong, 
disiplin, mandiri, salingmenolong, menghargai, kepedulian sosial dan lingkungan (Erliani, 2016). Jadi self esteem dapat dipengaruhi oleh motivasi altruistik siswa. Semakin tinggi harga diri seorang remaja semakin tinggi pula perilaku altruisme dan sebaliknya, semakin rendah harga diri seorang remaja semakin rendah pula perilaku altruisme.

Berdasarkan penelitian yang di lakukan oleh Fitri Nurri Afivah terdapat gejala bahwa siswa yang aktif dalam organisasi ekstrakurikuler, jarang mendapatkan sanksi sekolah dan siswa yang mampu mengutarakan pendapat kepada teman-temannya dan pendapat itu diterima oleh temantemannya, dan lebih sering menolong kepada temannya, sebagai contoh ketika istirahat mereka rela membelikan snack (makanan ringan) untuk temannya. Berbeda dengan siswa yang tidak mengikuti kegiatan ekstrakurikuler dan tidak mau mengapresiasikan pendapagnya didepan teman-temannya, mereka lebih cenderung membantu teman yang hanya dekat dengan dirinya saja (Afivah, 2016).

\section{Simpulan}

Simpulan dari hasil penelitian ini mengungkapkan bahwa self-esteem dan motivasi altruistis siswa yang mengikuti kegiatan pramuka di sekolah rata-rata berada pada kategori sedang dan terdapat hubungan yang signifikan antara self-esteem dengan motivasi altruistis siswa yang mengikuti kegiatan pramuka di sekolah. Kepada pembina pramuka di sekolah hendaknya menginternalisasikan setiap kegiatan pramuka dengan memasukkan nilai-nilai motivasi altruistis untuk menguatkan self-esteem siswa, kemudian untuk peneliti selanjutnya agar dapat meneliti tentang perbedaan self-esteem dan motivasi altruistis siswa yang mengikuti kegiatan pramuka dengan siswa yang mengikuti kegiatan Palang Merah Remaja (PMR)

\section{Ucapan Terimakasih}

Ucapan terimakasih penulis sampaikan kepada Ibu Dosi Juliawati, M.Pd., Kons dan Bapak Hengki Yandri, M.Pd., Kons., atas saran dan masukan terhadap hasil penelitian ini, serta support kepada penulis sehingga hasil penelitian ini bisa dipublikasikan secara resmi pada jurnal ini. Penulis juga mengucapkan terima kasih kepada Kepala Sekolah Menengah Pertama Negeri 7 Sungai Penuh yang telah memberikan izin kepada peneliti untuk mengumpulkan data penelitian ini.

\section{Referensi}

Afivah, F. N. (2016). Hubungan harga diri terhadap perilaku altruisme pada remaja kelas XI MAN Sumberoto Donomulyo (Doctoral dissertation, Universitas Islam Negeri Maulana Malik Ibrahim).

Alifah, S. N. (2016). Kontribusi kegiatan kepramukaan dalam meningkatkan Self Esteem siswa di MTs alAz̧har Sampung Ponorogo (Doctoral dissertation, STAIN Ponorogo).

Aliwanto. (2017). Analisis Aktivitas Belajar Siswa. Jurnal Konseling Gusjigang. 3(1)

Arifin, L. (2013). Upaya Konselor Dalam Membimbing Belajar Siswa Di Sekolah Dasar/Madrasah Ibtidaiyah. Jurnal Bimbingan Konseling Islam, 4(2), 201-218. 
Asytharika. (2016). Peningkatan Harga Diri (Self Esteem) dengan Layanan Konseling Kelompok pada Siswa Kelas VIII di SMP Negeri 26 Bandar lampung, (Skripsi)

Carpenter, J., \& Myers, C. K. (2010). Why volunteer? Evidence on the role of altruism, image, and incentives. Journal of Public Economics, 94(11-12), 911-920.

Desmita. (2014). Psikologi Perkembangan Peserta Didik. Bandung : Remaja Rosdakarya

Erliani, S. (2017). Peran Gerakan Pramuka untuk Membentuk Karakter Kepedulian Sosial dan Kemandirian (Studi Kasus di SDIT Ukhwah dan MIS An-Nuriyyah 2 Banjarmasin). AlAdzka: Jurnal Ilmiah Pendidikan Guru Madrasab Ibtidaiyah, 7(1), 35-52.

Hasan, B. (2013). Landasan Pendidikan. Pustaka Setia

Irawati, N., \& Hajat, N. (2012). Hubungan antara harga diri (self esteem) dengan prestasi belajar pada siswa SMKN 48 di Jakarta Timur. Jurnal Ilmiah Econosains, 10(2), 193-210.

Johnson, B. W., Redfield, D. L., Miller, R. L., \& Simpson, R. E. (1983). The Coopersmith selfesteem inventory: A construct validation study. Educational and Psychological Measurement, 43(3), 907-913.

Kementerian Pendidikan dan Kebudayaan Nomor 63 Tahun 2014 Tentang Pendidikan Kepramukaan Sebagai Ekstrakulikuler Wajib Pada Pendidikan Dasar dan Pendidikan Menengah

Kwarnas Gerakan Pramuka. (2013). Keputusan Musyawarah Nasional Gerakan Pramuka Tentang Anggaran Rumah Tangga (ART). Semarang

Nisa, K. (2015). Hubungan Antara Religiusitas dengan Perilaku Altruisme Santri Pondok Pesantren Hidayatul Hikmah (Thesis, Universitas Islam Negeri Sunan Ampel Surabaya).

Nopiarni, R., Yandri, H., \& Juliawati, D. (2020). Perilaku Membolos Siswa Sekolah Menengah Atas di Era Rovolusi Industri 4.0. Bikotetik (Bimbingan dan Konseling: Teori dan Praktik), 4(1), 21-24.

Nurdianto, S. (2016). Perbedaan kecerdasan moral dan perilaku altruisme siswa yang tinggal di pesantren dan non-pesantren di Madrasah Tsanawiyah Negeri Kediri 2 (Doctoral dissertation, Universitas Islam Negeri Maulana Malik Ibrahim).

Salahudin, Anas. (2010). Bimbingan dan Konseling. Bandung : Pustaka Setia

Suhron, M. (2017). Asuban Keperawatan Jiwa Konsep Self Esteem, Jakarta: MitraWacana Media.

Sukardi. (2013). Metodologi Penelitian Pendidikan. Jakarta: Bumi Aksara.

Sylvia, R. (2016). Hubungan self esteem dan motivasi belajar terhadap pendidikan kewarganegaraan. Jurnal Pendidikan Dasar, 7(2), 311-328.

Undang-Undang Republik Indonesia Nomor 20 Tahun 2003 Tentang Sistem Pendidikan Nasional.

Yandri, H., Fikri, M. K., \& Juliawati, D. (2019). Penerapan Perilaku Altruistik dalam Layanan Konseling Individu Oleh Guru Bimbingan dan Konseling di Sekolah. Tarbawi: Jurnal Ilmu Pendidikan, 15(1), 53-64.

Yandri, H., Juliawati, D., \& Afrifadela, N. (2020). Self Control Belajar Siswa di Sekolah dalam Menghadapi Era Revolusi Industri 4.0. Tarbawi: Jurnal Ilmu Pendidikan, 16(01), 77-86. 